\title{
Ocorrência de plantas daninhas no sistema lavoura-pecuária em função de sistemas de cultivo e corretivo de acidez
}

\author{
Renan Rodrigues Braga ${ }^{1}$, João Pedro Cury², Jose Barbosa dos Santos ${ }^{3}$, Eliza Catharina Mota Byrro ${ }^{1}$, Daniel \\ Valadão Silva², Felipe Paolinelli de Carvalho ${ }^{2}$, Karina Guimarães Ribeiro ${ }^{3}$
}

\begin{abstract}
RESUMO
Os estudos das interações entre plantas daninhas, culturas e sistemas de plantio podem proporcionar o entendimento de novas formas de implantação, recuperação e renovação das pastagens. Assim, objetivou-se estudar a fitossociologia de plantas daninhas em implantação de pastagem por meio da integração lavoura-pecuária, em cultivo safrinha. Admitindose a necessidade de aplicação de corretivo, os tratamentos resultaram da combinação de dois sistema de plantio (semeadura direta e aração seguida pela gradagem) e quatro doses de corretivo da acidez (0, 1/3, 1/2 e 1 vezes a recomendação). Observou-se que plantas do gênero Sida apresentam maiores índices de valor de importância em todos os tratamentos. As espécies Sida urens e Sida rhombifolia foram as mais representativas. Os índices de valor de importância do gênero Sida foram crescentes com as doses do corretivo, apresentando valores máximos com metade da dose recomendada de calcário, com posterior decréscimo. Ocorreram, também, espécies tóxicas aos animais de pastejo, além de gramíneas e leguminosas forrageiras, que podem ser benéficas ao sistema. As espécies de gramíneas perenes apresentaram maiores valores de importância em plantio convencional do que em plantio direto, possibilitando o uso de herbicidas específicos para o primeiro sistema. Comparando o plantio direto com o plantio convencional, o índice de similaridade foi igual a $81,1 \%$, o que é considerado alto. Em geral, o plantio convencional apresentou ainda maior densidade de plantas daninhas que o plantio direto.
\end{abstract}

Palavras-chave: Brachiaria brizantha, correção da acidez, levantamento fitossociológico, plantio direto, safrinha, Zea mays.

\section{ABSTRACT}

\section{Occurrence of weeds in the crop-livestock system as a function of cropping systems and acidity correction}

Studies on the interaction among weeds, crops and planting systems can provide new systems of pasture introduction, recovering, and renovation. This research aimed to study weed phytosociology in pasture implanted in the fallow cropping. Considering the need of liming application, the treatments followed the combination of two planting systems (no-tillage and plowing followed by harrowing) and four soil $\mathrm{pH}$ adjustment levels $(0,1 / 3,1 / 2$ and 1 time of the recommendation). It was observed that Sida species showed higher importance value indexes in all treatments. Sida urens and Sida rhombifolia were the most representative. Importance value indexes of plants from the Genus Sida were increased with corrective rates, showing maximum values with half of recommended lime rate, with posterior decrease. Besides grasses and forage legumes which can benefit the system, other species toxic to animals occurred. Perennial grasses showed higher importance value index under conventional planting than in no-tillage system,

Recebido para publicação em 27/07/2011 e aprovado em 04/10/2012

Engenheiro-Agrônomo. Mestrando em Produção Vegetal da Universidade Federal dos Vales do Jequitinhonha e Mucuri, Campus JK, Rodovia MGT 367, Km 583, 5000, Alto da Jacuba, 39100-000, Diamantina, Minas Gerais, Brasil. renanrbraga@yahoo.com.br; elizabyrro@hotmail.com

${ }^{2}$ Engenheiro-Agrônomo, Mestre. Universidade Federal dos Vales do Jequitinhonha e Mucuri, Campus JK, Rodovia MGT 367, Km 583, 5000, Alto da Jacuba, 39100-000, Diamantina, Minas Gerais, Brasil. joaopcury@yahoo.com.br; danielvaladaos@yahoo.com.br; felipepaolinelli_dm@hotmail.com

${ }^{3}$ Engenheiro-Agrônomo, Doutor. Universidade Federal dos Vales do Jequitinhonha e Mucuri, Centro de Ciências Agrárias, Campus JK, Rodovia MGT 367, Km 583, 5000, Alto da Jacuba, 39100-000, Diamantina, Minas Gerais, Brasil. jbarbosasantos@yahoo.com.br; karina_ufvjm@yahoo.com.br 
making possible the use of specific herbicides in conventional system. Comparing no-tillage and conventional systems, the similarity index was $81.1 \%$, which is considered high. In general, conventional planting system showed even higher weed density than no-tillage in the implementation of the integration system .

Key words: Brachiaria brizantha, soil acidity correction, phytosociologic assessment, no-tillage, fallow cropping, Zea mays.

\section{INTRODUÇÃO}

O cultivo extemporâneo de certas espécies anuais, como o do milho, denominado "safrinha", é importante e viável para os agricultores (Casagrande \& Fornasieri Filho, 2002), permitindo dois cultivos dessas espécies, por ano. No entanto, é um sistema com maiores riscos, por depender das condições climáticas, principalmente quanto à precipitação e temperatura (Cardoso et al., 2004). Além disso, podem ocorrer maiores perdas de rendimento da cultura, em razão do maior poder de competição das plantas daninhas, em situações específicas, como em ambientes degradados (Curtinhas et al., 2010).

O controle de plantas infestantes no milho é feito predominantemente pelo método químico, graças à eficiência, rapidez de operação e economia de custos (Jakelaitis et al., 2005). O atrazine é o principal herbicida utilizado nesta cultura, sendo aplicado no início do desenvolvimento do milho, em pré ou pós-emergência das plantas daninhas. Em integração lavoura-pecuária, o uso deste herbicida apenas em única aplicação pode não ser suficiente, pois as espécies daninhas são importantes mesmo após o período crítico de competição com a cultura anual, não sendo interessante que a forrageira escolhida desenvolva-se sob altos níveis de infestação. Kuva et al. (2007) comentam que, no cultivo da cana-de-açúcar, a escolha e o momento de aplicação do herbicida não incluem algumas variáveis importantes, como o conhecimento da comunidade vegetal, o que acontece também na maioria das culturas.

O conhecimento da população de plantas daninhas, com base na fitossociologia de espécies infestantes, é um fator de grande importância no seu manejo integrado (Oliveira \& Freitas, 2008). Braun-Blanquet (1979) define fitossociologia como o estudo das comunidades vegetais do ponto de vista florístico e estrutural. Os índices fitossociológicos são importantes para analisar o impacto que os sistemas de manejo agrícola exercem no crescimento e na ocupação de comunidades naturais de plantas não cultivadas, nos vários agroecossistemas existentes (Pitelli, 2000).

As plantas daninhas podem alterar sua dinâmica de infestação em função do tipo e da intensidade de tratos culturais (Duarte et al., 2007) e do manejo do solo (Jakelaitis et al., 2003a; Murphy et al., 2006). O conhecimento das espécies vegetais em determinado local pode indicar a condição desse ambiente. A exemplo, Cynodon dactylon indica uma condição de solo compactado e, Urtica urens, de excesso de nitrogênio e falta de cobre (Primavesi, 1992).

A utilização do plantio direto pode resultar em mais segurança ao produtor, por proporcionar maior capacidade de armazenar e disponibilizar água às plantas (Bescansa et al., 2006; Vita et al., 2007), pelo fato de o sistema radicular explorar regiões mais profundas do solo (Silva, et al., 2009) e também pelo fato de os tratos convencionais ocasionarem a degradação gradativa dos solos, diminuindo o seu potencial produtivo (Ferreira \& Lamas, 2010). Este sistema, normalmente, favorece as espécies daninhas anuais associadas a menor $\mathrm{pH}$ e menor teor de cálcio na camada superficial. De forma contrária, em sistema de plantio direto tende a ocorrer maior incidência de espécies daninhas perenes associadas a $\mathrm{pH}$ e teor de cálcio mais elevados nesta camada (Ferreira et al., 2007).

Estudos sobre a infestação de plantas daninhas, na implantação do sistema de integração lavoura-pecuária que envolva características do solo, como revolvimento e $\mathrm{pH}$, tornam-se necessários para minimizar os danos causados pelas plantas daninhas à cultura anual e à forrageira. Assim, objetivou-se, neste trabalho, estudar a fitossociologia de plantas daninhas, em dois sistemas de plantio e quatro doses de calcário, em implantação de pastagem na integração lavoura-pecuária, com cultivo de milho safrinha.

\section{MATERIAL E MÉTODOS}

O experimento foi conduzido a campo, na Fazenda Experimental do Moura, em Curvelo-MG, no período de janeiro a abril de 2009, em um Latossolo Vermelho-Amarelo onde antes eram cultivadas forrageiras para pastejo bovino. $\mathrm{O}$ solo onde o experimento foi realizado apresentou as seguintes características físicas e químicas: 71, 21 e $8 \mathrm{~g}$ $\mathrm{kg}^{-1}$, argila, silte e areia, respectivamente; $\mathrm{pH}$ (água) de 5,6; teor de matéria orgânica de $1,8 \mathrm{dag} \mathrm{kg}^{-1} ; \mathrm{Pe} \mathrm{K}$ de $1,8 \mathrm{e}$ $80 \mathrm{mg} \mathrm{dm}^{-3}$, respectivamente; $\mathrm{Ca}, \mathrm{Mg}, \mathrm{Al}, \mathrm{H}+\mathrm{Ale} \mathrm{CTC}_{\text {efetiva }}$ de 1,$0 ; 0,8 ; 0,8 ; 3,3 \mathrm{e} 2,8 \mathrm{cmol} \mathrm{dm}^{-3}$, respectivamente.

Aos 30 dias antes da aplicação do calcário, foi realizada a dessecação química da vegetação com o herbicida glyphosate $\left(1,08 \mathrm{~kg}\right.$ ia ha- $\left.{ }^{-1}\right)$, nas parcelas com sistema de 
plantio direto e, na área referente ao sistema de plantio convencional, essa vegetação foi incorporada pelo preparo mecânico do solo, com uma aração e duas gradagens a uma profundidade de $20 \mathrm{~cm}$. Após esse período, antes da aplicação do calcário, a vegetação remanescente na área do sistema de plantio direto foi roçada com utilização de roçadeira manual.

Adotou-se arranjo fatorial em esquema 2x4, constituído pela combinação de dois sistemas de plantio (direto, sem a incorporação do corretivo, e convencional, com a incorporação) e quatro doses de calcário $(0 ; 0,83 ; 1,25$ e 2,50 $\mathrm{tha}^{-1}$ ), sendo 2,50 $\mathrm{t} \mathrm{ha}^{-1}$ a dose recomendada para a cultura do milho no Estado de Minas Gerais (Alves et al., 1999). Os tratamentos foram delineados em blocos ao acaso, sendo cada um composto por duas faixas de solo, uma sujeita à aração e gradagem e outra, em sistema de semeadura direta. Aárea de cada parcela era de $39 \mathrm{~m}^{2}$ (3 m x $13 \mathrm{~m}$ de largura e comprimento, respectivamente), com quatro repetições. As doses de calcário $(\mathrm{PRNT}=80 \%)$ nas áreas sob sistema de plantio convencional e direto foram aplicadas manualmente, a lanço, na superfície do solo, sem incorporação e incorporado a $20 \mathrm{~cm}$ de profundidade, respectivamente, 30 dias antes da semeadura da cultura e da espécie forrageira.

Empregou-se uma adubação básica, a partir do formulado 4-14-8 ( $\left.-\mathrm{P}_{2} \mathrm{O}_{5}-\mathrm{K}_{2} \mathrm{O}\right)$, na dose de $570 \mathrm{~kg} \mathrm{ha}^{-1}$. Para o consórcio lavoura-pecuária, optou-se pela semeadura do milho, variedade $\mathrm{Al} 25$, no espaçamento de $1 \mathrm{~m}$ entre linhas e 16 plantas $\mathrm{m}^{-1}$. Para a forrageira, optou-se pela espécie Brachiaria brizantha cv. Marandu, semeada em duas fileiras distadas de $50 \mathrm{~cm}$, na entrelinha do milho, sendo utilizados $7 \mathrm{~kg} \mathrm{ha}^{-1}$ de sementes $(\mathrm{VC}=50 \%)$, plantadas simultaneamente com a semeadura do milho, ambas a profundidade de $2 \mathrm{~cm}$.

As avaliações fitossociológicas de plantas daninhas foram realizadas aos 30 e 60 dias após emergência do milho (DAE). Utilizou-se o método do quadrado aleatório, sendo um quadrado vazado de $0,5 \mathrm{~m}$ de comprimento lateral $\left(0,25 \mathrm{~m}^{2}\right)$, lançado duas vezes, aleatoriamente, em área representativa de cada parcela (Erasmo et al., 2004). Posteriormente, fez-se a identificação das espécies daninhas delimitadas pelo quadrado. Após o levantamento fitossociológico, realizado aos $30 \mathrm{DAE}$, foi realizada a adubação nitrogenada, em cobertura, na linha de plantio do milho, na dose de $100 \mathrm{~kg} \mathrm{ha}^{-1}$ de $\mathrm{N}$, e aplicado o herbicida atrazine, na dose de $2,5 \mathrm{~kg}$ ia ha ${ }^{-1}$, em área total, para o controle das espécies infestantes.

Após a identificação das plantas, foram determinados índices fitossociológicos propostos por Mueller-Dombois \& Ellenberg (1974), sendo eles: frequência relativa (FRR), densidade relativa (DER), abundância relativa (ABR) e índice de valor de importância (IVI). Para o cálculo desses índices, utilizaram-se as seguintes fórmulas:

$$
\begin{aligned}
& \operatorname{FRR}(\%)=\frac{\text { Frequência da espécie }(\mathrm{FRE}) * 100}{\text { Frequência total de todas as espécies }} \\
& \operatorname{DER}(\%)=\frac{\text { Densidade da espécie }(\mathrm{DEN}) * 100}{\text { Densidade total das espécies }} \\
& \operatorname{ABR}(\%)=\frac{\text { Abundância das espécies }(\mathrm{ABU}) * 100}{\text { Abundância total das espécies }} \\
& \mathrm{IVI}=\mathrm{FRR}+\mathrm{DER}+\mathrm{ABR}
\end{aligned}
$$

Calculou-se também o índice de similaridade de Sorensen (IS) (Sorensen, 1972), por meio da fórmula:

$$
\operatorname{IS}(\%)=(2 a / b+c) * 100
$$

em que: $a=$ número de espécies comuns nas duas áreas; $b$ e $c=$ número total de espécies nas respectivas áreas comparadas. Este índice é máximo (100\%), quando todas as espécies são comuns às áreas, e mínimo (0\%), quando não existem espécies comuns.

\section{RESULTADOS E DISCUSSÃO}

Considerando-se todos os tratamentos, foram identificadas 22 espécies, distribuídas em oito famílias, com destaque para Malvaceae, Poaceae e Asteraceae, que apresentaram maiores índices de valor de importância (IVI), em ordem decrescente (Figuras 1 e 2). Macedo et al. (2003), avaliando fitossociologicamente áreas de póscolheita do milho em várzeas do rio São Francisco - MG, também encontraram Malvaceae e Asteraceae como famílias dominantes.

O gênero Sida apresentou maior IVI em todos os tratamentos, constando das espécies S. Urens, $S$. rhombifolia e $S$. cordifolia, sendo que a soma dos IVI destas espécies foi superior a 50\% da importância em todas as áreas (Figuras 1 e 2). Níveis de infestações semelhantes foram observados por Macedo et al. (2003), durante a pós-colheita do milho solteiro. Porém, resultados diferentes foram observados por Duarte et al. (2007), em área cultivada por vários anos com soja e milho safrinha. Os autores verificaram que Cenchrus echinatus foi a espécie que apresentou o maior IVI. Adicionalmente, o IVI representa a importância das espécies dentro de cada área estudada (MuellerDombois \& Ellenberg, 1974).

A densidade e abundância relativas são os índices responsáveis pelos altos IVIs do gênero Sida, indicando que plantas pertencentes a este gênero podem estar presentes em grande número e na forma de reboleira nas áreas agrícolas. O cultivo de pastagens antes da instalação do experimento pode ter contribuído para esta alta infestação, pois estas espécies estão comumente presentes e em altas infestações neste ambiente (Kissmann \& Groth, 2000; Tuffi Santos et al., 2004). 


\section{Plantio convencional}
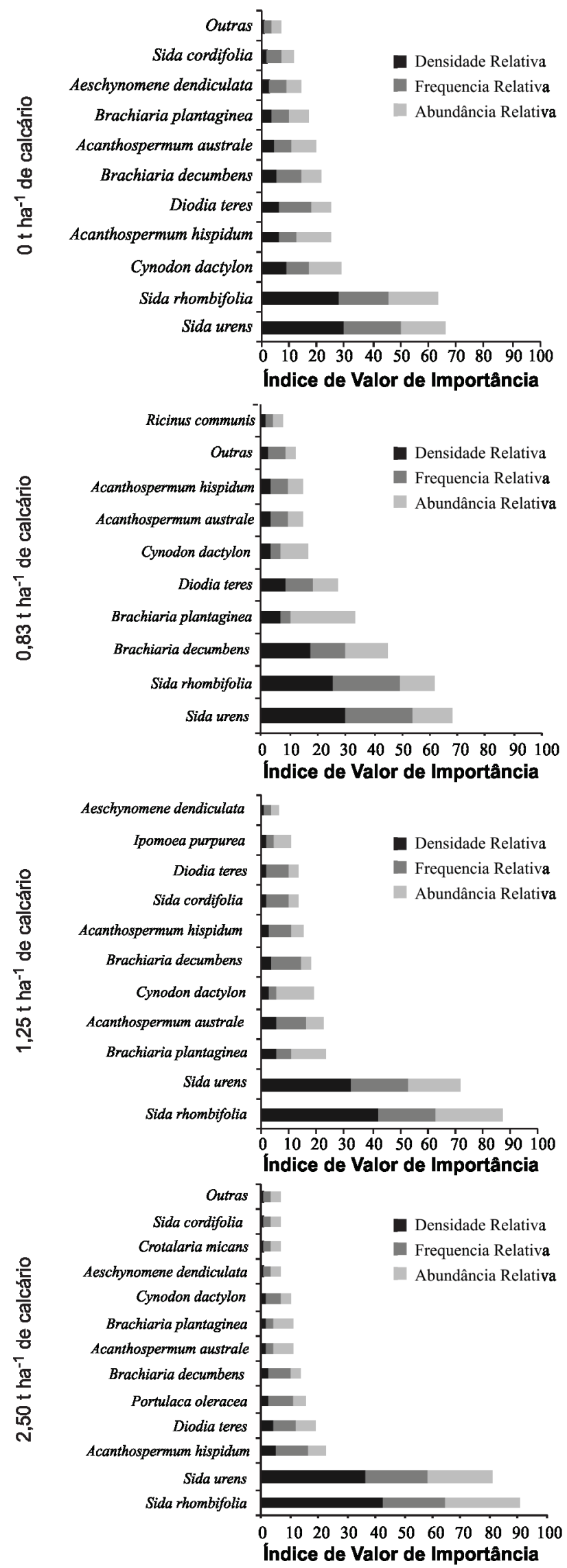

Plantio direto
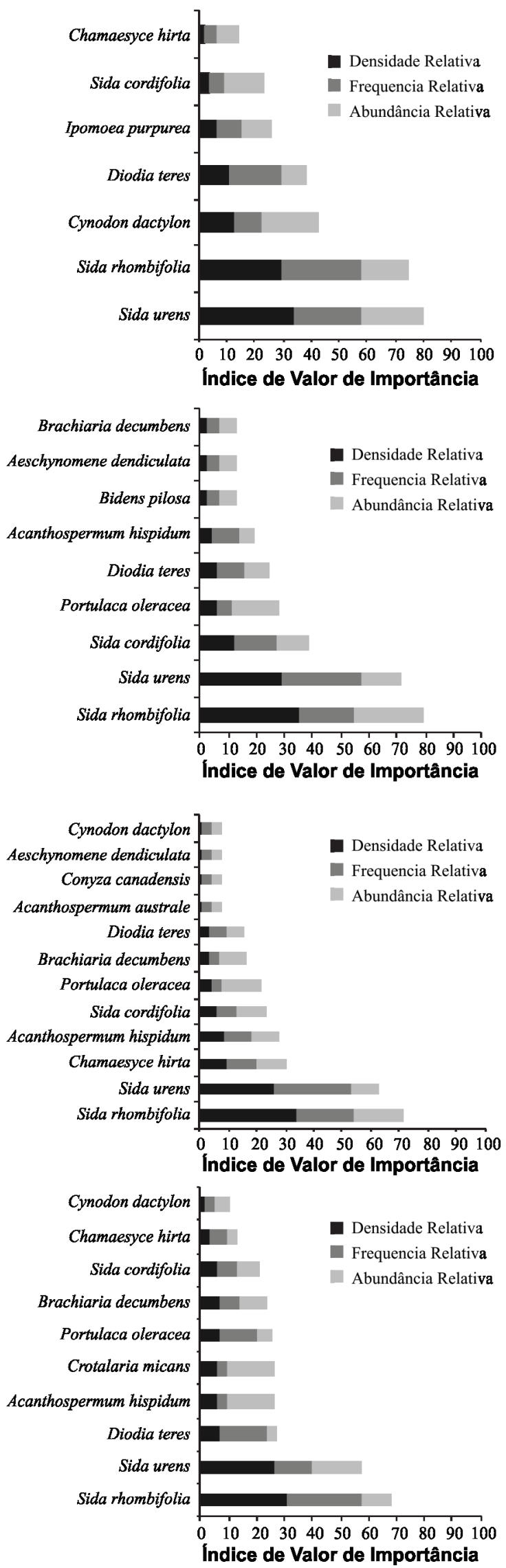

Figura 1. Índices fitossociológicos aos 30 dias após emergência do milho. 


\section{Plantio convencional}
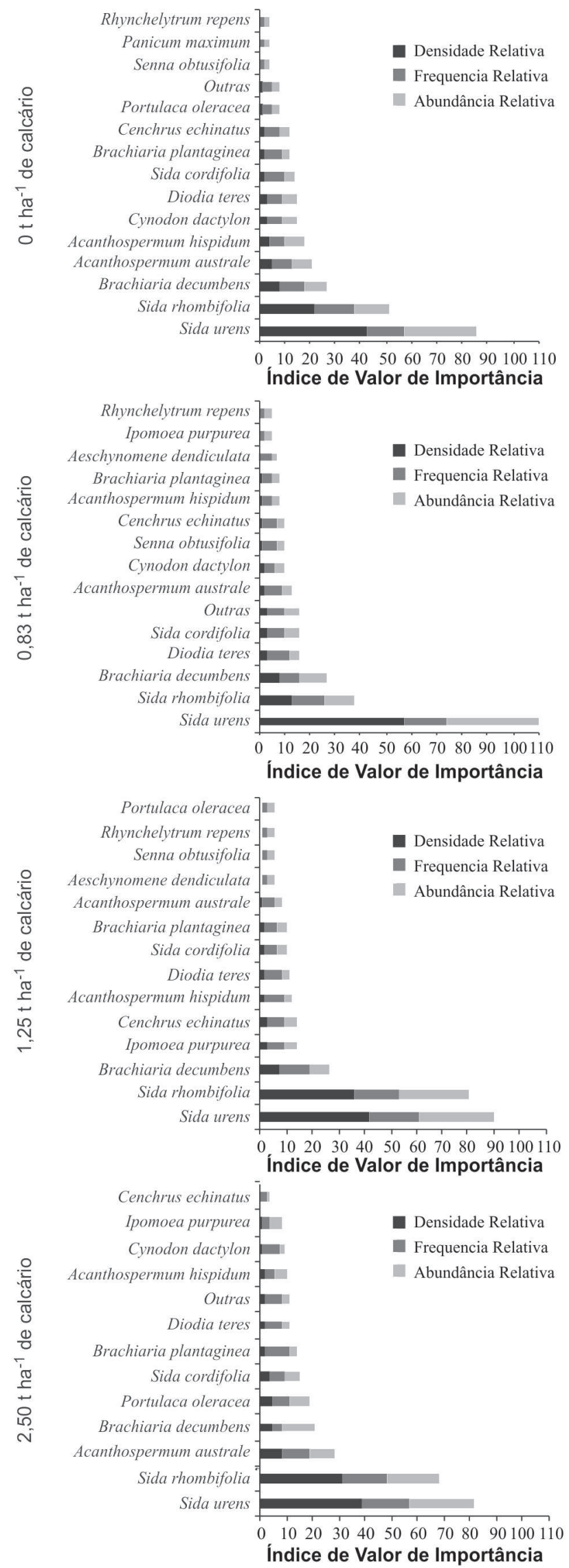

Plantio direto

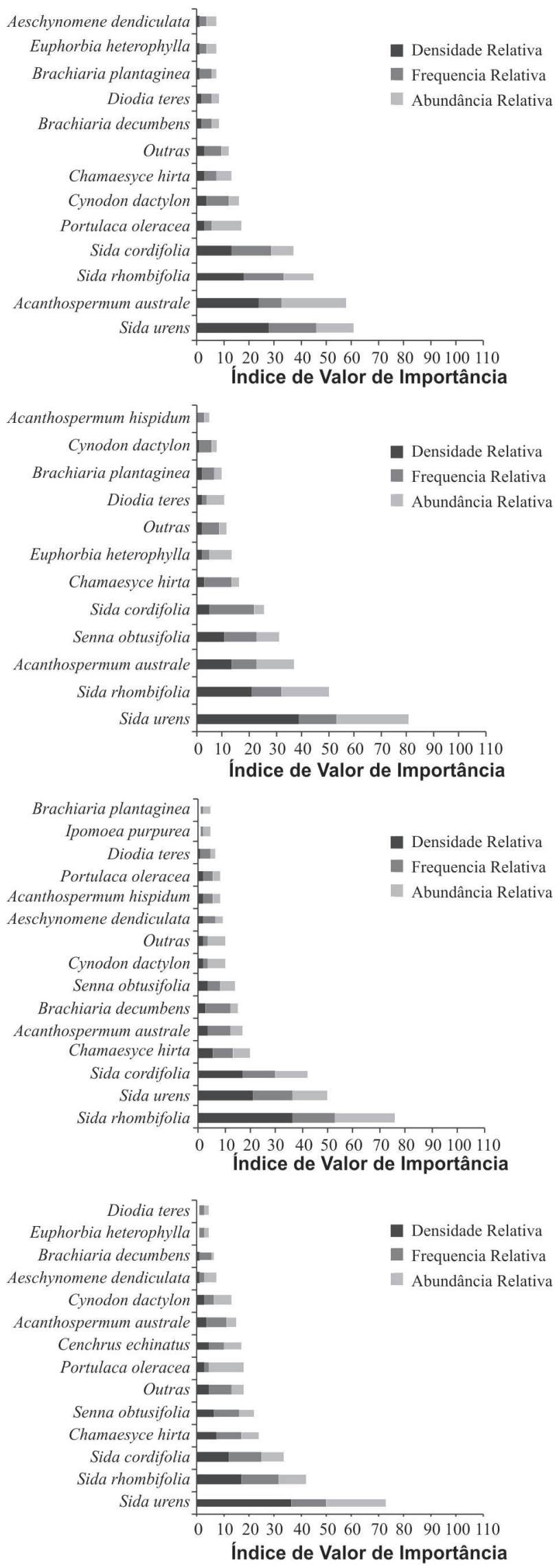

Figura 2. Índices fitossociológicos aos 60 dias após emergência do milho.

Rev. Ceres, Viçosa, v. 59, n.5, p. 646-653, set/out, 2012 
Observou-se maior IVI das espécies do gênero Sida no sistema de plantio convencional (Figuras 1 e 2). Estes resultados corroboram os obtidos por Martins et al. (1999), os quais verificaram que a espécie $S$. rhombifolia diminui sua agressividade à medida que se aumenta a quantidade de cobertura morta sobre o solo. A palha, fornecida pela adoção do plantio direto, reduz a incidência dos raios solares e a amplitude térmica sobre o banco de sementes do solo, o que impede a germinação das sementes dormentes e quiescentes ali presentes; também dificulta a emergência e o início do desenvolvimento de outras plantas daninhas, principalmente daquelas que apresentam poucas reservas em seus propágulos, não sendo capazes de vencer esta barreira (Duarte et al., 2007).

Observou-se comportamento semelhante entre as espécies do gênero Sida nos diferentes sistemas de plantio, com acréscimo nos IVIs à medida que se aumentou a dose do corretivo, apresentando valores máximos na dose de 1,25 t ha ${ }^{-1}$ de calcário, com posterior decréscimo (Figuras 1 e 2). Estes resultados estão de acordo com os de Kissmann \& Groth (1999), os quais concluíram que a espécie $S$. rhombifolia desenvolve-se melhor em solos adubados e corrigidos. Isto indica que uma subdose de calcário já é suficiente para a expressão do potencial destas espécies.

Espécies da família Fabaceae merecem destaque por fixarem nitrogênio biologicamente e, também, por serem consumidas pelos animais, o que pode contribuir para a melhoria de suas dietas (Tuffi Santos et al., 2004). As espécies encontradas foram Aeschynomene denticulata, Crotalaria micans e Senna obtusifolia. Entretanto, $C$. micans e S. obtusifolia apresentam certo risco, pois podem ser tóxicas aos animais. C. micans é tóxica durante sua frutificação, e, como o gado tem preferência por ela (Lorenzi, 2008), deve ser evitado seu consumo durante esse período.

Crotalaria micans ocorreu apenas na primeira avaliação fitossociológica, na maior dose de calcário, nos dois sistemas de plantio (Figura 1), o que evidencia maior germinação de suas sementes em solos bem corrigidos e adaptação a diferentes condições edáficas e de manejo da área.

A espécie $S$. obtusifolia ocorreu apenas no levantamento realizado aos 60 dias após emergência do milho (DAE) (Figura 2). O índice mais alto para esta espécie foi a frequência relativa (FRR), que se refere à distribuição das espécies nas parcelas em relação ao total de espécies (Tuffi Santos et al., 2004), indicando que a espécie se apresenta bem distribuída na área. Observou-se, também, que $S$. obtusifolia apresenta maiores valores de IVI em plantio direto, demonstrando que as condições edáficas proporcionadas pelo não revolvimento do solo podem beneficiar a germinação de suas sementes.

Aeschynomene denticulata está presente na maioria dos tratamentos, embora sempre com baixos valores de IVI (Figuras 1 e 2).
Algumas espécies da família Poaceae estiveram presentes nos levantamentos, porém, muitas delas não são prejudiciais a animais em pastejo, por também serem consumidas pelo gado como forrageiras, como é o caso da Brachiaria decumbens e B. plantaginea, que são espécies do mesmo gênero cultivado e que apresentam boas características forrageiras para algumas regiões. Plantas de Cynodon dactylon e Panicum maximum são utilizadas para pastejo e apresentam diversos cultivares e boas características nutricionais para os animais. Rhynchelytrum repens é forrageira disseminada em grandes extensões do Brasil.

Quanto à infestação nos diferentes sistemas de plantio, observou-se que, quando somado os IVIs das espécies de gramíneas, estes apresentaram sempre maiores valores no plantio convencional, corroborando os resultados obtidos por Duarte Júnior et al. (2009). Isto possibilita o uso de herbicidas específicos para controlar estas espécies, reduzindo, assim, o uso desnecessário de outras moléculas químicas. Contudo, após anos subsequentes, utilizando diferentes práticas agronômicas, manejo do solo e aplicação de herbicidas, poderão ocorrer alterações fitossociológicas, modificando as espécies de maior dominância (Godoy et al., 1995).

Aos 30 DAE do milho, Chamaecise hirta estava presente apenas nos tratamentos em que se adotou plantio direto, com exceção daquele com a dose de $0,83 \mathrm{t} \mathrm{ha}^{-1}$ de calcário (Figura 1). Já no levantamento realizado aos 60 DAE, esta espécie emergiu em todos os tratamentos neste mesmo sistema de plantio (Figura 2). Observou-se, também, acréscimo no IVI com o aumento da dose de calcário em ambas as avaliações (Figuras 1 e 2).

A espécie Diodia teres apareceu em todas as parcelas avaliadas, apresentando altos valores de frequência relativa (FRR) em relação aos demais índices. Aos 30 DAE, esta espécie obteve maiores IVIs nas parcelas sob plantio direto. Já na fitossociologia realizada aos 60 DAE, a importância foi maior nos tratamentos em plantio convencional (Figuras 1 e 2). Este último sistema pode ter retardado a germinação desta espécie, pelo fato de as sementes terem sido enterradas a maior profundidade. Esta espécie é uma conhecida invasora de pastagens, sendo necessário seu controle após a colheita do milho.

Aos 30 DAE, Portulaca oleracea emergiu apenas com a utilização do calcário em plantio direto, e, em plantio convencional, somente na maior dose do corretivo (Figura 1). Isto evidencia a necessidade da correção da acidez superficial do solo para a germinação e o desenvolvimento inicial desta espécie. Na maioria dos tratamentos onde foi encontrada, apresenta alta abundância relativa, possivelmente por ser muito prolífera; entretanto, não apresenta um bom método de dispersão.

Acanthospermum australe e A. hispidum estiveram presentes na maioria dos tratamentos. Estas espécies apre- 
sentaram maiores IVIs quando se aplicou 2,50 t ha-1 de calcário em plantio convencional e nas menores doses do corretivo em plantio direto (Figuras 1 e 2).

Independentemente da aplicação de calcário, os valores de densidade absoluta de plantas daninhas, em sistema de plantio convencional e direto, aos 30 DAE, foram de 249 e 151 plantas $\mathrm{m}^{-2}$, e, aos 60 DAE, de 503 e 408 plantas $\mathrm{m}^{-2}$, respectivamente. A maior emergência no plantio convencional também foi verificada por Pereira \& Velini (2003). As principais causas podem ser a quebra de dormência das sementes e a maior disseminação e infestação de espécies de propagação vegetativa em sistema convencional de cultivo (Jakelaitis et al., 2003b), além de que, em plantio direto, ocorre maior predação de sementes, sabendo que estas permanecem sobre a superfície do solo, sendo alvos para insetos e micro-organismos.

Comparando-se as mesmas doses de calcário em diferentes sistemas de plantio, observou-se aumento no índice de similaridade (IS) com o incremento das doses de calcário (Tabela 1). Aos 30 DAE, o IS foi maior nas áreas de plantio direto (Tabela 1), o que evidencia menor diversidade florística em áreas cultivadas com este sistema.

Os valores observados para IS entre as mesmas áreas, aos 30 e aos 60 DAE do milho, nas doses de $0 ; 0,83 ; 1,25$ e 2,50 t ha ${ }^{-1}$ de calcário, para o plantio direto e convencional, foram de 77, 72, 80 e 85\%, e 60, 48, 81 e 67\%, respectivamente. Observaram-se maiores valores de IS, em plantio convencional e direto, nas doses de 1,25 e 2,50 $\mathrm{t} \mathrm{ha}^{-1}$ de calcário, respectivamente.

O IS entre plantio direto e plantio convencional, independentemente das aplicações de calcário e das diferentes épocas de avaliação, foi igual a 81,1\%, o que é considerado alto. Resultado semelhante foi encontrado por Duarte Júnior et al. (2009), verificando que mesmo diferentes sistemas de plantio podem proporcionar similaridade na infestação.

A elevada similaridade pode ser devida à proximidade entre as áreas avaliadas com diferentes sistemas de cultivo, haja vista que menores semelhanças de infestação são encontradas quando se trata de áreas distintas (Macedo et al., 2003). No entanto, é provável que, a longo prazo, ocorra redução do IS entre os dois sistemas, pois eles tendem a alterar a dinâmica de infestação e a composição botânica da comunidade natural de plantas não cultivadas, de acordo com a intensidade, regularidade e o tempo de utilização do sistema, e, ainda, conforme os tipos de tratos culturais e de manejo do solo (Zanin et al., 1997; Silva et al., 2005).

Tabela 1. Índices de similaridade aos 30 dias após emergência do milho (DAE), acima da diagonal e aos 60 DAE abaixo da diagonal

\begin{tabular}{lcccccccc}
\hline & PD-0,00 & PD-0,83 & PD-1,25 & PD-2,50 & PC-0,00 & PC-0,83 & PC-1,25 & PC-2,50 \\
\hline PD-0,00 & - & 84,2 & 95,2 & 90,9 & 58,8 & 73,7 & 81,8 & 70,0 \\
PD-0,83 & 86,7 & - & 80,0 & 76,2 & 50,0 & 55,6 & 66,7 & 63,2 \\
PD-1,25 & 82,8 & 89,7 & - & 87,0 & 66,7 & 70,0 & 78,3 & 66,7 \\
PD-2,50 & 85,7 & 85,7 & 81,5 & - & 52,6 & 76,2 & 83,3 & 81,8 \\
PC-0,00 & 71,4 & 71,4 & 66,7 & 76,9 & - & 50,0 & 63,2 & 70,6 \\
PC-0,83 & 74,1 & 74,1 & 61,5 & 72,0 & 80,0 & - & 76,2 & 73,7 \\
PC-1,25 & 80,0 & 86,7 & 82,8 & 85,7 & 85,7 & 81,5 & - & 81,8 \\
PC-2,50 & 75,9 & 75,9 & 71,4 & 74,1 & 88,9 & 76,9 & 82,8 & - \\
\hline
\end{tabular}

PD: plantio direto, PC: plantio convencional; $0 ; 0,83 ; 1,25 ; 2,50$ : são as respectivas doses de calcário em t ha-1.

\section{CONCLUSÕES}

As espécies Sida rhombifolia e S. urens foram as mais importantes neste sistema de integração lavoura-pecuária.

As espécies de plantas daninhas apresentaram alta similaridade entre os sistemas avaliados.

A utilização do plantio direto resultou em menor densidade de plantas daninhas, sendo este sistema mais eficiente para o controle cultural das espécies infestantes.

\section{AGRADECIMENTOS}

Ao Conselho Nacional de Desenvolvimento Científico e Tecnológico (CNPq), à Fundação de Amparo à Pes- quisa do Estado de Minas Gerais (FAPEMIG) e à Coordenação de Aperfeiçoamento de Pessoal de Nível Superior (CAPES), pelo apoio financeiro na execução deste trabalho.

\section{REFERÊNCIAS}

Alves VMC, Vasconcellos CA, Freire FM, Pitta GVE, França GE, Rodrigues Filho A, Araújo JM, Vieira JR \& Loureiro JE (1999) Milho. In: Ribeiro AC, Guimarães PTG \& Alvarez V VH (Eds.) Recomendação para o uso de corretivos e fertilizantes em Minas Gerais: $5^{\text {a }}$ aproximação. Viçosa, CFSEMG. p.314-316.

Bescansa P, Imaz MJ, Virto I, Enrique A \& Hoogmoed WB (2006) Soil water retention as affected by tillage and residue management in semiarid Spain. Soil \& Tillage Research, 87:19-27.

Braun-Blanquet V (1979) Fitosociología, bases para el estudio de las comunidades vegetales. Madrid, H. Blume. 820p. 
Cardoso OC, Faria RT \& Folegatti MV (2004) Simulação do rendimento e riscos climáticos para o milho safrinha em Londrina - PR, utilizando o modelo CERES-Maize. Engenharia Agrícola, 24:291-300.

Casagrande JRR \& Fornasieri Filho D (2002) Adubação nitrogenada na cultura do milho safrinha. Pesquisa Agropecuária Brasileira, 37:33-40.

Curtinhas JN, Santos JB, Vicente NMF \& Perez AL (2010) Caracterização fitossociológica da vegetação herbácea de áreas alteradas pela atividade agropecuária na região do Médio Vale do Rio Doce, Minas Gerais. Revista Ceres, 57:321-329.

Duarte AP, Silva AC \& Deuber R (2007) Plantas infestantes em lavouras de milho safrinha, sob diferentes manejos, no médio Paranapanema. Planta Daninha, 25:285-291.

Duarte Júnior JB, Coelho FC \& Freitas SP (2009) Dinâmica de populações de plantas daninhas na cana-de-açúcar em sistema de plantio direto e convencional. Semina: Ciências Agrárias, 30:595-612.

Erasmo EAL, Pinheiro LLA \& Costa NV (2004) Levantamento fitossociológico das comunidades de plantas infestantes em áreas de produção de arroz irrigado cultivado sob diferentes sistemas de manejo. Planta Daninha, 22:195-201.

Ferreira ACB \& Lamas FM (2010) Espécies vegetais para cobertura do solo: influência sobre plantas daninhas e a produtividade do algodoeiro em sistema plantio direto. Revista Ceres, 57:778786 .

Ferreira OGL, Siewerdt L, Medeiros RB, Levien R, Favreto R \& Pedroso CES (2007) Atributos químicos do solo e regeneração de espécies espontâneas originárias do banco de sementes em campo nativo sob diferentes sistemas de cultivo. Revista Brasileira de Agrociência, 13:81-89.

Godoy G, Vega J \& Pitty A (1995) El tipo de labranza afecta la flora y la distribución vertical del banco de semillas de malezas. Ceiba, 36:217-229.

Jakelaitis A, Ferreira LR, Silva AA, Agnes EL, Miranda GV \& Machado AFL (2003a) Efeitos de sistemas de manejo sobre a população de tiririca. Planta Daninha, 21:89-95.

Jakelaitis A, Ferreira LR, Silva AA, Agnes EL, Miranda GV \& Machado AFL (2003b) Dinâmica populacional de plantas daninhas sob diferentes sistemas de manejo nas culturas de milho e feijão. Planta Daninha, 21:71-79.

Jakelaitis A, Silva AA, Ferreira LR, Silva AF, Pereira JL \& Viana RG (2005) Efeitos de herbicidas no consórcio de milho com Brachiaria brizantha. Planta Daninha, 23:69-78.

Kissmann KG \& Groth D (2000) Plantas infestantes e nocivas. $2^{\mathrm{a}}$ ed. São Paulo, BASF. Tomo III. 978p.

Kuva MA, Pitelli RA, Salgado TP \& Alves PLCA (2007) Fitossociologia de comunidades de plantas daninhas em agroecossistema cana-crua. Planta Daninha, 25:501-511.
Lorenzi H (2008) Plantas daninhas do Brasil: terrestres, aquáticas, parasitas e tóxicas. $4^{\mathrm{a}}$ ed. Nova Odessa, Instituto Plantarum. $640 \mathrm{p}$.

Macedo JF, Brandão M \& Lara JFR (2003) Plantas daninhas na pós-colheita de milho nas várzeas do rio São Francisco, em Minas Gerais. Planta Daninha, 21:239-248.

Martins D, Velini ED, Martins CC \& Souza LS (1999) Emergência em campo de dicotiledôneas infestantes em solo coberto com palha de cana-de-açúcar. Planta Daninha, 17:151-161.

Mueller-Dombois D \& Ellenberg H (1974) Aims and methods of vegetation ecology. New York, John Wiley. 547p.

Murphy SD, Clements DR, Belaoussoff S, Kevan PG \& Swanton CJ (2006) Promotion of weed species diversity and reduction of weed seedbanks with conservation tillage and crop rotation. Weed Science, 54:69-77.

Oliveira AR \& Freitas SP (2008) Levantamento fitossociológico de plantas daninhas em áreas de produção de cana-de-açúcar. Planta Daninha, 26:33-46.

Pereira FAR \& Velini ED (2003) Sistemas de cultivo no cerrado e dinâmica de populações de plantas daninhas. Planta Daninha, 21:355-363

Pitelli RA (2000) Estudos fitossociológicos em comunidades infestantes de agroecossistemas. Jornal ConsHerb, 1:1-7.

Primavesi A (1992) Agricultura sustentável. São Paulo, Nobel. 142 p.

Silva AA, Silva CSW, Souza CM, Souza BA, Fagundes JL, Falleiro RM \& Sediyama CS (2005) Aspectos fitossociológicos da comunidade de plantas daninhas na cultura do feijão sob diferentes sistemas de preparo do solo. Planta Daninha, 23:17-24.

Silva AA, Galon L, Ferreira FA, Tironi SP, Ferreira EA, Silva AF, Aspiazú I \& Agnes EL (2009) Sistema de plantio direto na palhada e seu impacto na agricultura brasileira. Revista Ceres, 56:496-506.

Sorensen TA (1972) Method of establishing groups of equal amplitude in plant society based on similarity of species content. In: Odun EP (Ed.) Ecologia. $3^{\text {a }}$ ed. México, Interamericana. $640 \mathrm{p}$.

Tuffi Santos LD, Santos IC, Oliveira CH, Santos MV, Ferreira FA \& Queiroz DS (2004) Levantamento fitossociológico em pastagens degradadas sob condições de várzea. Planta Daninha, 22:343-349.

Vita P, Paolo E, Fecondo G, Fonzo N \& Pisante M (2007) Notillage and convencional tillage effects on durun wheat yield, grain quality and soil moisture content in southern Italy. Soil \& Tillage Research, 92:69-78.

Zanin G, Otto S, Riello L \& Borin M (1997) Ecological interpretation of weed flora dynamics under different tillage systems. Agriculture, Ecosystems \& Environment, 66:177-188. 